GUSTAVO HENRIQUE CAMPOS SOUZA

\title{
A EFETIVAÇÃO DO MELHOR INTERESSE POR MEIO DOS MECANISMOS DE PARTICIPAÇÃO DA CRIANÇA NO DIREITO INTERNACIONAL PRIVADO DA FAMÍLIA
}

Dissertação de Mestrado

Orientador: Prof. Dr. Gustavo Ferraz de Campos Monaco

UNIVERSIDADE DE SÃO PAULO

FACULDADE DE DIREITO

São Paulo - SP 


\title{
A EFETIVAÇÃO DO MELHOR INTERESSE POR MEIO DOS MECANISMOS DE PARTICIPAÇÃO DA CRIANÇA NO DIREITO INTERNACIONAL PRIVADO DA FAMÍLIA
}

\begin{abstract}
Dissertação apresentada à Banca Examinadora do Programa de Pós-Graduação em Direito, da Faculdade de Direito da Universidade de São Paulo, como exigência parcial para obtenção do título de Mestre em Direito, na área de concentração Direito Internacional e Comparado, sob orientação do Professor Associado Gustavo Ferraz de Campos Monaco.
\end{abstract}

\section{UNIVERSIDADE DE SÃO PAULO}

FACULDADE DE DIREITO

São Paulo - SP 
Catalogação da Publicação

Serviço de Biblioteca e Documentação

Faculdade de Direito da Universidade de São Paulo

Souza, Gustavo Henrique Campos

A efetivação do melhor interesse por meio dos mecanismos de participação da criança no direito internacional privado da família/Gustavo Henrique Campos Souza; orientador Gustavo Ferraz de Campos Monaco -- São Paulo, 2018

$142 \mathrm{f}$.

Dissertação (Mestrado - Programa de Pós-Graduação em Direito Internacional) - Faculdade de Direito, Universidade de São Paulo, 2018.

1. Adoção Internacional. 2. Convenção sobre os Direitos da Criança. 3. Efetividade. 4. Guarda Internacional. 5. Subtração Internacional. I. Monaco, Gustavo Ferraz de Campos, oriente. II. Título. 
Nome: SOUZA, Gustavo Henrique Campos

Título: A efetivação do melhor interesse por meio dos mecanismos de participação da criança no direito internacional privado da família

Dissertação apresentada à Faculdade de Direito da Universidade de São Paulo para a obtenção do título de Mestre em Direito.

Aprovada em:

Banca Examinadora

Prof (a). Dr(a). Instituição:

Julgamento: Assinatura:

Prof (a). Dr(a). Instituição:

Julgamento: Assinatura:

Prof (a). Dr(a). Instituição:

Julgamento: Assinatura: 
A meus pais, Olegário e Maria Amélia, pelo incentivo, dedicação, companheirismo e com paciência incentivaram-me a não perder a esperança e o não desistir dos sonhos de vida.

A meu irmão, Eduardo Luís (in memoriam), mesmo ausente, está sempre presente na lembrança. 


\section{AGRADECIMENTOS}

Agradecer nem sempre é fácil, posto que podemos ser traídos pela memória e esquecer alguém que na construção da pesquisa a fez tornar-se possível, porém tentarei.

A Deus por ensinar que fomos "criados a Sua imagem e semelhança", por isso devemos ter gratidão para com Ele por fazermos parte deste universo.

Ao meu orientador, Gustavo Ferraz de Campos Monaco, por transmitir os conhecimentos e tornar o trabalho possível, orientando-me e confiando em mim.

Aos professores do curso de pós-graduação da Universidade de São Paulo, pelos ensinamentos e trocas de experiências.

Aos colegas de caminhada, por dividir anseios e expectativas de se fazer algo em contribuição para a melhoria da sociedade brasileira.

Aos meus avós, tios e tias, primos e primas que sempre estiveram presentes nos momentos alegres e tristes, auxiliando no compreender dos obstáculos da vida.

Aos membros da banca de qualificação, Nina Ranieri e Cláudia Perrone-Moisés, pelas sugestões e experiências acrescentadas para o enriquecimento desta pesquisa.

À Ilda Cordeiro que sempre ficou na "torcida" pelo meu crescimento e ajudou-me junto a meus pais a ver a vida com o olhar da fé.

Aos colegas de trabalho, que me apoiaram para que o término da pesquisa fosse concretizado. 
Família é uma escolha nossa de modo livre e engrandecedor quando os laços do amor se fazem presentes. Eles não deixam que hajam abandonos, esquecimentos, distâncias, ressentimentos. E ainda, por meio desses laços, se chega ao respeito, ao carinho, à compreensão que o ser humano é a mais bela criação.

Maria A. da S. Campos Souza 


\section{RESUMO}

SOUZA, G. H. C. A efetivação do melhor interesse por meio dos mecanismos de participação da criança no direito internacional privado da família. 2018. $142 \mathrm{f}$. Dissertação (Mestrado) - Faculdade de Direito, Universidade de São Paulo, São Paulo, 2018.

O princípio do melhor interesse da criança, entendido como um guia hermenêutico central, permitiu consolidar mudanças no paradigma dos direitos da criança de maneira a universalizá-los não somente em documentos internacionais, mas também em incentivar a promoção de meios efetivos e específicos para a realização desses direitos. A flexibilidade e permeabilidade desse princípio permite uma interpretação conjunta - e necessária - há alguns outros direitos, como o direito de participação da criança, que encontra um propício campo de aplicação no direito internacional privado da família. Nesse aspecto, a presente pesquisa teve como objetivo analisar a efetivação do melhor interesse por meio dos mecanismos de participação da criança no direito internacional privado da família, a partir da ampla ratificação da Convenção sobre os direitos da criança. Para tanto, essa pesquisa se utilizou do método histórico-dialético e do método indutivo. Após analisar temas como a subtração internacional, a adoção internacional e a guarda internacional, essa pesquisa não vislumbrou, qualquer cenário de participação da criança no direito internacional privado da família que não considere o princípio do melhor interesse. A análise da participação da criança além da contida no artigo 12 da Convenção sobre os Direitos da Criança se fez necessária para compreender sua conexão ao princípio do melhor interesse da criança; bem como, na visão desse autor, entender seu requisito de validade nos procedimentos do direito internacional privado da família e a importância na sua efetivação. Por fim, essa pesquisa concluiu que a efetivação e efetividade do melhor interesse por meio dos mecanismos de participação da criança no direito internacional privado da família não se vincula ao caráter procedimental da participação, e sim ao seu caráter substancial, que age para implementar as interpretações relacionadas ao conceito do melhor interesse nos Estados.

Palavras-chave: Adoção internacional. Convenção sobre os Direitos da Criança. Efetividade. Guarda internacional de crianças. Subtração internacional de crianças. 


\begin{abstract}
SOUZA, G. H. C. The realization of the best interest through the mechanisms of child participation in private international family law. 2018. $140 \mathrm{f}$. Dissertação (Mestrado) Faculdade de Direito, Universidade de São Paulo, São Paulo, 2018.

The best interest of the child principle, understood as a central hermeneutical guide, has allowed to consolidate changes in the paradigm of the rights of the child universalizing them not only in international documents, but also encouraging the promotion of effective and specific means for conducting these rights. The flexibility and permeability of this principle allows a joint - and necessary - interpretation with some other rights, such as the right child participation, which finds a suitable field of application in private international family law. In this aspect, this research aims to analyze the effectiveness of the best interest through the mechanisms of child participation in private international family law, based on the broad ratification of the Convention on the Rights of the Child. For that, this research was based on the historical-dialectical and the inductive methods. After analyzing topics such as international child abduction, international child adoption and international child custody, this research did not envisage any scenario of child's participation in the private international family law that does not consider the best interest principle. The analysis of child participation beyond Article 12 of the Convention on the Rights of the Child was necessary to understand its connection with the best interests of the child principle; as well as, in the view of this author, to understand it as a validity requirement in the procedures of private international family law and the importance in its effectiveness. Finally, this research concluded that the effectiveness of the best interests of the child principle through the mechanisms of child participation in private international family law is not related to the procedural nature of participation, but to its substantial character, which acts to implement the interpretations related to the concept of the best interest in the States.
\end{abstract}

Keywords: International adoption. Convention on the Rights of the Child. Effectiveness. International child custody. International child abduction. 


\section{SUMÁRIO}

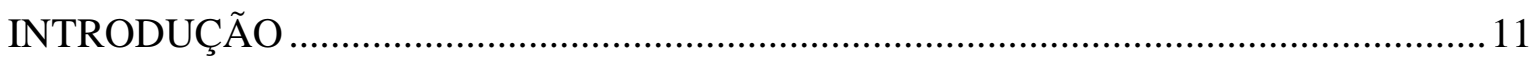

CAPÍTULO 1 - O PRINCÍPIO DO MELHOR INTERESSE DA CRIANÇA.................... 14 CAPÍTULO 2 - UMA ANÁLISE CRÍTICA SOBRE A PARTICIPAÇÃO DA CRIANÇA

CAPÍTULO 3 - A PARTICIPAÇÃO DA CRIANÇA ENTRE PROCEDIMENTO E

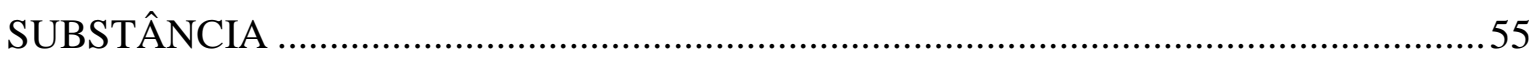

3.1 Da Natureza e do Escopo da Participação...............................................................56

3.2 A Participação e sua implementação pelos Estados....................................................66

CAPÍTULO 4 - A PARTICIPAÇÃO DA CRIANÇA NO DIREITO INTERNACIONAL

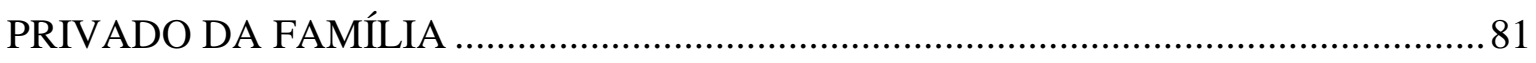

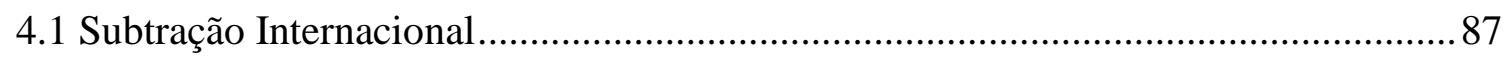

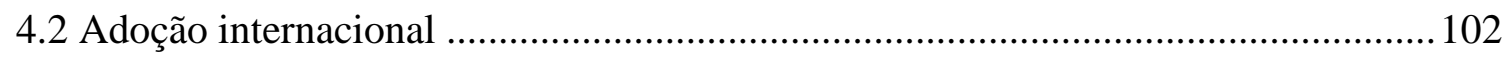

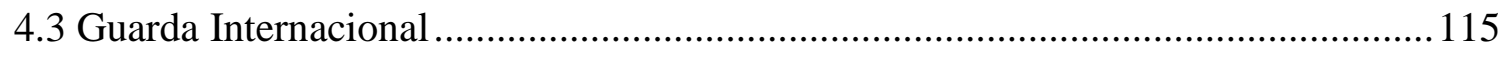

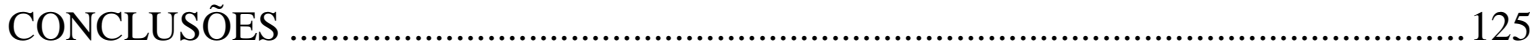

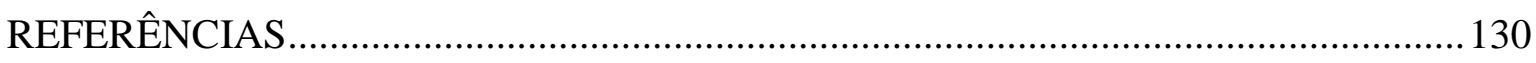




\section{INTRODUÇÃO}

A compreensão da infância e da criança varia, de acordo com o tempo, local e sociedade. Das populares construções ocidentais da infância, a identificarem psicologicamente cada uma das características etárias, modo de tratamento e atitudes esperadas, a criança hoje é encarada como um ser autônomo e sujeito de direitos. Isso implicou em mudanças paradigmáticas no sistema de proteção e promoção dos direitos da criança, a se iniciar com a Declaração Universal dos Direitos Humanos, de 1948 e, mais tardiamente, a Convenção sobre os direitos da criança de 1989.

Com isso, o princípio do melhor interesse foi alçado como um valor central no que diz respeito aos direitos da criança. Seu conceito deliberadamente indefinido permite a flexibilidade necessária para se fazer presente em áreas como o direito internacional privado da família. Ainda, traz consigo outros direitos, relacionados à adoção, à participação, ao direito de convivência familiar, dentre outros.

É a partir do melhor interesse que os Estados elaboram as políticas estatais de proteção e promoção dos direitos da criança, com sistemas judicias e administrativos no qual a criança passa a ser o centro do processo de decisão, devendo ter oportunidades de uma participação substancial e procedimento, quebrando com a visão assistencialista de outrora.

Para Hart, a participação seria não apenas um direito em si mesmo, mas um meio vital para a consolidação dos outros direitos da criança, impulsionando o desenvolver de novos esforços e métodos por parte da comunidade internacional ${ }^{1}$.

Não bastam simples comparações entre possibilidade de aplicação da já muito estudada teoria da participação dos adultos às crianças; ou ainda a classificação das formas de participação da criança de maneira a falsamente hierarquizá-las. E sim em buscar definir parâmetros que permitam a efetivação e análise crítica dos mecanismos de participação diante das diferentes figuras do direito internacional privado da família, como forma de efetivação do princípio do melhor interesse.

Do exposto, a presente pesquisa tem como objetivo analisar a efetivação do melhor interesse por meio dos mecanismos de participação da criança no direito internacional privado da família, a partir da ampla ratificação da Convenção sobre os direitos da criança,

\footnotetext{
1 HART, Jason. Children's Participation and International Development: Attending to the Political. International Journal of Children's Rights, 16, Londres: Martinus Nijhoff Publishers, 2008, p. 407-418.
} 
propulsora nas mudanças de concepção e no novo paradigma fomentador da doutrina da proteção integral da criança e do adolescente ${ }^{2}$.

Assim, essa pesquisa pretende pesquisar criticamente as teorias da participação da criança, na busca de um conteúdo plenamente aplicável ao direito internacional privado da família. Se buscará ainda analisar a natureza, escopo e implementação da participação e da Convenção pelos Estados-parte. Por fim, serão verificados os mecanismos de participação da criança em institutos de direito internacional privado da família e a efetivação do melhor interesse.

Para isso, este trabalho foi organizado em quatro capítulos.

O primeiro capítulo analisou, de forma breve, o princípio do melhor interesse, traçando conceitos e objetivos específicos, bem como analisando a sua presença na Convenção sobre os Direitos da Criança, a partir de interpretação do artigo $3^{\circ}$ da Convenção. Por sua vez, o segundo capítulo analisou a participação a partir da concepção contida no artigo $12^{\circ}$ da Convenção das Nações Unidas sobre os Direitos da Criança, de 1989. Na busca de expandir a concepção sobre o tema, foram analisadas as concepções da participação e as teorias da participação das crianças, tomando como base teórica os estudos de Hart e Lansdown, sendo feito o seu estudo crítico. Em seguida, buscou-se formular um conceito sobre participação para os procedimentos e processos do direito de família internacional, a permear, em geral, todas as outras análises.

No capítulo terceiro, se analisou a implementação da Convenção pelos Estados, tendo como paradoxo o estudo de Jean Koh Peters. Em seguida, se analisou a natureza e o escopo da participação, como prevista no artigo 12; as premissas necessárias para a sua implementação; e, enfim, os entraves à implementação prática da participação.

No quarto capítulo, se analisou os mecanismos de participação no direito internacional privado, subdividindo-os em temas como o da subtração internacional, da adoção internacional e da guarda internacional. O método a ser utilizado nesse capítulo será o de demonstrar a aplicação da participação no direito de família, e analisá-lo nas Convenções de Direito Internacional Privado relacionadas ao tema, identificando os mecanismos de participação e a sua inter-relação com a efetivação do princípio do melhor interesse.

Por fim, essa pesquisa se utilizou da seguinte metodologia: (i) método históricodialético - revisão da doutrina dedicada ao Direito Internacional Privado, Direito de Família

${ }^{2}$ PIOVESAN, Flávia. Temas de Direitos Humanos. 6. ed. São Paulo: Saraiva, 2013, p. 410. 
Internacional, Participação e ao Direito Internacional dos Direitos Humanos; (ii) método indutivo - partindo das análises específicas anteriores, pretende-se sustentar uma posição com vistas a melhor compreender o tema e eventualmente sugerir alterações. 


\section{CONCLUSÕES}

A busca por uma conceituação universal sobre o que seria o princípio do melhor interesse da criança serviu como ponto nevrálgico e motivador para o desenvolvimento dessa pesquisa. A inquietude motivou investigações, que fizeram todo o cerne da pesquisa se voltar às interpretações advindas da conjunção do princípio do melhor interesse, previsto no artigo $3^{\circ}$ da Convenção sobre os Direitos da Criança, ao direito da criança de ser ouvida em todos os procedimentos que a ela digam respeito, o artigo 12 da Convenção.

A primeira conclusão que este trabalho chega é que, de fato, o princípio do melhor interesse não possui uma conceituação objetiva e universal, e que defender essa conceituação, como esse autor pretendeu fazer em um início de pesquisa, seria impedir sua efetivação enquanto overwhelming paramount principle, a consolidar as mudanças de paradigma necessárias aos direitos da criança, agora como um sujeito de direito.

O princípio do melhor interesse é, como bem trazem os Comentários do Comitê sobre os direitos da criança, constituído por três diferentes conceitos: o do direito substantivo; o do princípio legal interpretativo e o da regra de procedimento. Esse amplo espectro interpretativo permite que seu objetivo fundamental de assegurar à criança proteção e cuidados necessários ao seu desenvolvimento, bem como promover as reformas necessárias à sua implementação, sejam feitos de maneira universal, não só com o apoio da ordem interna, e sim da ordem internacional.

Os parâmetros mínimos e de validade a serem considerados para a eficácia do princípio do melhor interesse, que compartilham muito com as características apresentada pela doutrina em relação aos direitos humanos, garantem a objetividade necessária para a sua implementação pelos Estados, sem, contudo, perder a sua adaptabilidade necessária para uma aplicação individualizada aos casos concretos.

Ao princípio do melhor interesse é atribuído o que se denominou nesse trabalho uma deliberada indefinição, conexa à flexibilidade necessária para sua aplicação em todos os casos relativos à criança, um parâmetro universal; e a sua permeabilidade, para figurar como consideração primária em diversas áreas de direito. No entanto, flexibilidade e permeabilidade não só justificam a interdisciplinaridade do princípio, e sim uma conexão intrínseca e extrínseca a outros direitos da criança, como o da participação, que encontra um fértil campo de aplicação no direito internacional privado de família. 
Essa culmina na segunda conclusão dessa pesquisa, relativa ao direito de participação da criança. Não bastaria para analisar os mecanismos de participação da criança no direito internacional privado da família e traçar conclusões sobre a efetivação do melhor interesse, se apegar apenas à definição do artigo 12 da Convenção sobre os Direitos da Criança. E sim de que seria necessária uma análise pormenorizada dos conceitos e teorias da participação, na busca de traçar uma definição que se adeque à análise da atuação no direito de família.

Essa análise permitiu identificar que o artigo 12 estabelece aos Estados-parte da Convenção, por óbvio, uma obrigação de garantir o direito de participação, respeitando o sistema jurídico e a vontade da criança. No entanto, não permite que crianças fora de contextos sociais interiores e comuns, expressem sua opinião e sejam protegidas como bem pretende a conjunção dos artigos 12 e $3^{\circ}$ da Convenção.

Uma das intenções primordiais da participação, ser capaz de formar um senso de conveniência e pertencimento da criança, implicando no seu desenvolvimento e realização enquanto cidadã, estaria, na visão desse autor, ameaçada pela própria generalidade do artigo 12, já que beneficia grupos e não desafia Estados e organizações a enfrentarem uma multiplicidade de fatores. E sim os incentiva a mimetizar instituições e processos para incluir a participação da criança baseado nos instrumentos participativos dos adultos.

Essa análise da participação permitiu, além de criar as bases para que fosse considerada em esferas administrativas judiciais e extrajudiciais que foram analisadas in concreto nos capítulos finais da pesquisa, concluir que a participação da criança em uma escala real e não mimetizada está vinculada à necessidade de desenvolver processos que informem e permitam o amplo acesso da criança e considerem que a participação é um direito fundamental de cidadania, base do Estado Democrático.

A terceira conclusão traçada nessa pesquisa se relaciona à proposição de um novo conceito para a participação da criança, a saber o direito da criança de expressar-se e engajarse de maneira direta ou por meio de representantes, em todos os assuntos a ela relacionados no direito internacional privado da família, respeitado seu desenvolvimento mental e formas de expressão, e levando em consideração seu bem-estar superior e o exercício de sua cidadania. E esse conceito está claramente relacionado à efetividade do melhor interesse.

Feitas as considerações sobre a participação, a pesquisa avançou sobre outra necessidade advinda da indagação de como analisar os mecanismos de participação no direito internacional privado da família e a efetivação do melhor interesse sem, contudo, verificar como os Estados-parte implementavam as disposições contidas na natureza e no escopo da participação, bem como solucionam os entraves daí advindos. 
Uma quarta conclusão obtida, a partir da análise de dados relacionados à pesquisa sistematizada pela Yale Law School sobre os Estados signatários e seus sistemas de promoção e proteção dos direitos da criança, é que uma ínfima porcentagem possuía em 2005 provisões que garantiam uma participação direta ou indireta da criança, sendo que mais de 67 Estados sequer possuíam previsões para que a criança fosse ouvida em procedimentos judiciais e administrativos, ou ainda, nenhum procedimento de proteção das crianças.

Os motivos apontados para esse alarmante dado é que a participação da criança é concebida pela grande maioria dos 194 Estados signatários da Convenção apenas em seu caráter procedimental. O caráter substancial, por sua vez, era relegado pelos Estados e apontava para a dificuldade em traduzir a participação do artigo 12 da Convenção e sua implementação prática.

Importante ressaltar aqui a discordância sobre a crítica de alguns autores de que a Convenção é falha ao não prever expressamente o método apto a concretizar os princípios individuais e provisões contidos em seu texto. Essa crítica parte de um pressuposto frágil de que um tratado poderia criar uma obrigação de reforma constituinte aos Estados. Ainda, desconsidera que essa opção implicaria em uma menor adesão ou ratificação com reservas da Convenção, sob a alegação de que esse suposto método iria ferir a ordem pública. E, por fim, desconsidera a multiplicidade de soluções legislativas dentre os Estados-parte sobre o status hierárquico da Convenção e a já existente efetividade dos seus dispositivos.

Frente à forte carga principiológica que a Convenção possui, entender a participação da criança conexa ao princípio do melhor interesse da criança conexo; bem como um requisito de validade aos procedimentos de direito internacional privado da família parece, ao autor dessa pesquisa, uma conclusão apta a enfrentar a omissão dos Estados e a falta de implementação de medidas de caráter político com o fim de proporcionar eficácia e efetividade aos dispositivos convencionais; bem como evitar embates se a exceção de ordem pública seria alegável diante desses princípios e direitos.

A implementação prática do direito à participação leva a pesquisa para uma quinta conclusão, ou seja, a falta de um consenso legal no que tange a materialização da participação nos procedimentos de direito internacional privado da família, sua operacionalização e a efetivação do melhor interesse.

Analisar como integrar essas crianças a todos os processos e procedimentos, em acordo com o melhor interesse, exigiria uma sistematização que reforçasse o papel do artigo 12 como paramount principle; e a exigir que a obrigação positiva prevista no artigo $4^{\circ}$ fosse 
cumprida, isto é, a adoção de medidas administrativas legislativas e outras fossem executadas pelo Estado.

A sexta conclusão é que a interpretação da Convenção deve ser, como defende Dolinger, dualista, com dispositivos autoexecutáveis, como o melhor interesse e da participação, claramente ligados a conceitos principiológicos e de direitos humanos fundamentais; e outros cuja efetividade e eficácia estariam vinculadas à adoção de medidas de caráter político.

Assim, estaria certo de que um direito humano fundamental da criança, a participação; conexo a um princípio paradigma, o melhor interesse, seriam interpretados de maneira conjunta e garantiriam os direitos da criança nas múltiplas ordens, mesmo diante das barreiras por parte dos Estados-parte.

Por fim, a introdução do quarto capítulo dessa pesquisa teve por objetivo dirimir quaisquer dúvidas sobre a possibilidade de participação no direito de família, passando a abordar formas diretas e indiretas de participação da criança, que se adequariam aos mecanismos de participação previstos nos temas da subtração, adoção e guarda internacional de crianças.

Como observado, nos três temas analisados há uma clara possibilidade de participação da criança, em seu caráter substancial e procedimental. Essa participação está atrelada não somente à previsão ou não em Convenções sobre o tema, já que pode ser contornada por meio de exercícios hermenêuticos extensivamente demonstrados nessa pesquisa. Acima de tudo, essa possibilidade está atrelada a uma interpretação conjunta da participação e princípio do melhor interesse da criança, com a consequente efetivação desse princípio.

Assim, é essa interpretação que garante a efetivação do melhor interesse com o delineamento de mecanismos de participação direta e indireta da criança, ancorados tanto na Convenção sobre os Direitos da Criança e nas Convenções da Haia; quanto no caráter paradigmático do princípio do melhor interesse, permitindo transpor as barreiras enfrentadas desde o conceito da participação até sua implementação pelos Estados.

Não se vislumbra, como uma conclusão final para essa pesquisa, qualquer cenário de participação da criança no direito internacional privado da família que não considere o princípio do melhor interesse. A efetivação e efetividade por meio dos mecanismos de participação da criança no direito internacional privado da família não se vincula ao caráter procedimental da participação, e sim ao seu caráter substancial, que age para implementar 
as interpretações relacionadas ao conceito do melhor interesse nos regimes dos Estadosparte. 


\section{REFERÊNCIAS}

AKEL, Ana Carolina Silveira. Guarda Compartilhada: um avanço para a família. São Paulo: Atlas, 2010, p. 3-4.

ALEXY, Robert. Teoria dos direitos fundamentais. Trad. Virgílio Afonso da Silva. 2. ed. São Paulo: Malheiros, 2008, p. 90-91.

ALONSO, Angela. As teorias dos movimentos sociais: um balanço do debate. São Paulo: Lua Nova, n. 76, 2009, p. 49-86.

ANSELL, Nicola. Children, Youth and Development. New York: Routledge, 2005, p. 227.

ARAÚJO, Leila Cavallieri de. A Adoção Internacional. Boletim Terre des Homes, n.19, de julho de 1990.

ARAUJO, Nadia de. Direito internacional privado: teoria e prática brasileira. 5. ed. atualizada e ampliada. Rio de Janeiro: Renovar, 2011, p. 80.

ARCHARD, David. John Locke's Children. In. TURNER, S. The Philosopher's Child: Critical Essays in the Western Tradition, Rochester: University of Rochester Press, 1987.

. Children 's Rights and childhood. London: Routledge, 1993.

ARIÈS, Philippe. Centuries of childhoold. New York: Random House, 1962. In: MILNE, Brian. The History and Theory of Children 's Citizenship in Contemporary Societies. New York: Springer, 2013, p. 61.

ARNSTEIN, Sherry R. 'Ladder of citizen participation'. In: Journal of The American Institute of Planners Association, 35:4, 1979, p.217.

BAERT, Patrick. Algumas limitações das explicações da escolha racional na Ciência Política e na Sociologia. Revista Brasileira de Ciências Sociais, São Paulo, v. 12, n. 35, oct. 1997. In: SCHEEFFER, Fernando. Teoria da escolha racional: a evidenciação do homo economicus? Revista Eletrônica dos Pós-Graduandos em Sociologia Política da UFSC. Florianópolis. v. 10, n. 1, jan./jun., 2013, ISSN 1806-5023, p. 34-35.

BAPTISTA MACHADO, João. Lições de Direito Internacional Privado. 3. ed. (reimp.). Coimbra: Almedina, 2015.

BARBOZA, Heloisa Helena Gomes. Melhor interesse da criança e do adolescente (princípio do). In: TORRES, Ricardo Lobo; KATAOKA, Eduardo Takemi; GALDINO, Flavio (org.). Dicionário de princípios jurídicos. Rio de Janeiro: Elsevier, 2011, p. 835-840.

BARBOZA, Heloisa Helena. Efeitos Jurídicos do parentesco sociofetivo. In: Revista da Faculdade de Direito da UERJ-RFD, Rio de Janeiro, v. 2, n. 24, 2013, p. 111-125. 
BEAUMONT, Paul. The Hague Convention on International Child Abduction, Oxford: Oxford Private International Law Series, 1999, p. 257.

BELIZE. Families and children act. Chapter 173. The subsidiary laws of Belize as at $31^{\text {st }}$ Octuber, 2003. Disponível em: < https://www.oas.org/dil/Families_and_Children_ Subsidiary_Act_Belize.pdf $>$ Acesso em: 20 de jun. 2017.

BENNET, Margareth H. Judicial and administrative co-operation in family law matters: co-operation in child abduction and similar cases. Address at the Hagues's anniversary international law conference presented by T.M.C. Asser Instituut, $4^{\text {th }}$ July, 1998.

BILDER, Richard B. An overview of international human rights law. In: HANNUM, Hurst (Editor). Guide to international human rights practice. 2. ed. Philadelphia: University of Pennsylvania Press, 1992.

BIOCCA, Stella M. Derecho internacional privado: un nuevo enfoque. Tomo I. Buenos Aires: Lajouane, 2004.

BIRCHALL, Johnston; SIMMONS, Richard. What motivate members to participate in the governance of consumer co-operatives? A study of Co-operative group. Research Report No. 2. Escócia: Stirling University, January, 2004.

BRASIL. Decreto n 3.413 de 14 de abril de 2000. Ementa. Diário Oficial da República Federativa do Brasil, Brasília, DF, 17 de abril de 2000. Disponível em:

<https://www.planalto.gov.br/ccivil_03/decreto/D3413.htm>. Acesso em: 05 jun. 2015.

Decreto $N^{\circ} 3.987$, de 21 de junho de 1999. Promulga a Convenção Relativa à Proteção das Crianças e à Cooperação em Matéria de Adoção Internacional, concluída na Haia, em 29 de maio de 1993. Disponível em: < http://www.planalto.gov.br/ccivil_03/ decreto/d3087.htm> Acesso em: 10 abr. de 2017.

Decreto $N^{\circ}$ 6.949, de 25 de agosto de 2009. Promulga a Convenção Internacional sobre os Direitos das Pessoas com Deficiência e seu Protocolo Facultativo, assinados em Nova York, em 30 de março de 2007). Disponível em: < http://www.planalto.gov.br/ ccivil_03/_ato2007-2010/2009/decreto/d6949.htm>. Acesso em: 10 abr. 2017.

. Decreto n. 99.719 de 21 de novembro de 1990. Promulga a Convenção sobre os Direitos da Criança. Disponível em:< http://www.planalto.gov.br/ccivil_03/decreto/19901994/d99710.htm> Acesso em: 19 ago. 2017.

Decreto $N^{\circ} 7.030$, de 14 de dezembro de 2009. Promulga a Convenção de Viena sobre o Direito dos Tratados, concluída em 23 de maio de 1969, com reserva aos Artigos 25 e 66. Disponível em: < http://www.planalto.gov.br/ccivil_03/_ato20072010/2009/decreto/d7030.htm> Acesso em: 10 jun. 2017.

Emenda Constitucional $N^{\circ} 65$, de 13 de julho de 2010. Altera a denominação do Capítulo VIII da Constituição Federal e modifica o seu art. 227, para cuidar dos interesses da juventude. Disponível em: <http://www.planalto.gov.br/ccivil_03/constituicao/ emendas/emc/emc65.htm> Acesso em: 1 ago. 2017. 
Decreto n 3.413 de 14 de abril de 2000. Ementa. Diário Oficial da República Federativa do Brasil, Brasília, DF, 17 de abril de 2000. Disponível em: <https://www.planalto.gov.br/ccivil_03/decreto/D3413.htm.> Acesso em: 05 jun. 2015.

Decreto. n. 3.413 de 14 de abril de 2000. Promulga a Convenção sobre os Aspectos Civis do Sequestro Internacional de Crianças, concluída na cidade de Haia, em 25 de outubro de 1980. Disponível em: <http://www.planalto.gov.br/ccivil_03/decreto/ d3413.htm>. Acesso em: 4 nov. 2017.

. Constituição da República Federativa do Brasil, de 5 de outubro de 1988. Diário

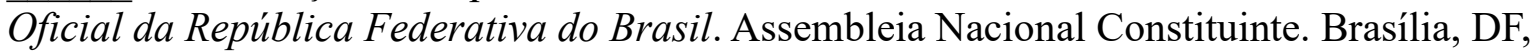
Cap.VII, p.25. Disponível em: $<$ http://www.planalto.gov.br/ccivil_03/Constituicao/ DOUconstituicao88.pdf> Acesso em: 10 out. 2017.

. Lei n. 8.069 de 13 de julho de 1990. Dispõe sobre o Estatuto da Criança e do Adolescente e dá outras providências. Disponível em: $<$ http://www.planalto.gov.br/ ccivil_03/leis/L8069.htm>. Acesso em 13 out. 2017.

Lei 13.015 de 16 de março de 2015. Código de Processo Civil. Disponível em: < http://www.planalto.gov.br/ccivil_03/_ato2015-2018/2015/lei/113105.htm>. Acesso em 24 $\operatorname{dez} 2017$.

. Decreto n. 3.087 de 21 de junho de 1999. Promulga a Convenção Relativa à Proteção das Crianças e à Cooperação em Matéria de Adoção Internacional, concluída na Haia, em 29 de maio de 1993. Disponível em: <http://www.planalto.gov.br/ccivil_03/ decreto/d3087.htm>. Acesso em: 26 dez. 2017.

. Decreto-Lei n. 4.657 de 4 de setembro de 1942. Lei de Introdução às normas do Direito Brasileiro. Disponível em: $<\mathrm{http}: /$ www.planalto.gov.br/ccivil_03/decretolei/Del4657compilado.htm>. Acesso em: 26 dez. 2017.

Lei n. 8.069 de 13 de julho de 1990. Dispõe sobre o Estatuto da Criança e do Adolescente e dá outras providências. Disponível em: < http://www.planalto.gov.br/ ccivil_03/leis/L8069.htm>. Acesso em: 26 dez. 2017.

. Constituição da República Federativa do Brasil, de 5 de outubro de 1988. Diário Oficial da República Federativa do Brasil. Assembleia Nacional Constituinte. Brasília, DF, Cap. VII, p. 25. Disponível em: <http://www.planalto.gov.br/ccivil_03/Constituicao/ DOUconstituicao88.pdf> Acesso em: 10 out. 2017.

BORRÁS, Alegria. La protección internacional del niño y del adulto como expresión de la materialización del derecho internacional privado. Similitudes y contrastes'. The internaional protection of the child and adult as expressed in private and international law: Similarities and differences. In: Pacis Artes. Obra homenaje al Profesor J. D. Gonzáles Campos, Madrid: Univ. Autonoma de Madrid, 2005, II.

BUCHER, Andreas. L'enfant en droit international privé. Paris: L.G.D.J, 2003. . La Famille en droit international privé. Recueil des Cours, The Hague/Boston/London: Martinus Nijhoff Publishers, v. 283, 2000. 
CALMON, Petrônio. Fundamentos da mediação e da conciliação. Rio de Janeiro: Forense, 2007.

CAMARGO, Solano de. O Direito da Criança de ser ouvida - Aspectos Internacionais. In: MONACO, Gustavo Ferraz de. FULCHIRON, Huges. (Org.). Famílias Internacionais: seus direitos, seus deveres. São Paulo: Intelecto, 2016. p. 258.

CAMARGO, Solano de. Forum Shopping: a escolha da jurisdição mais favorável. 1. ed. São Paulo: Intelecto Editora, 2017.

CANÇADO TRINDADE, Antonio Augusto. O direito internacional em um mundo em transformação. Rio de Janeiro: Renovar, 2002.

CANTWELL, Nigel. The Best Interests of the Child in Intercountry Adoption, Innocenti Insight, Florence: UNICEF Office of Research, 2014.

CAIRNS, Liam. Participation with purpose. In: TISDALL, E. Kay; M. DAVIS, John; PROUT, Alan; HILL, Malcolm. Children, Young People and Social Inclusion, Participation for What? Bristol: Policy Press, 2006, p. 217.

CARVALHO RAMOS, André de. Teoria geral dos direitos humanos na ordem internacional. 2. ed. São Paulo: Saraiva, 2012.

CARREIRA, Denise. (Coord.). A Participação de crianças e adolescentes e os Planos de Educação. São Paulo: Ação Educativa, 2013, $1^{\text {a }}$ edição.

CASHMORE, Judy; PARKINSON, Patrick. Children's participation in family law disputes: The views of children, parents, lawyers and counsellors. Family Matters, 2009, $\mathrm{n}^{\circ} 82,15-21$.

CASTRO, Mônica Mata Machado. Sujeito e estrutura no comportamento eleitoral. Revista Brasileira de Ciências Sociais, n. 20, São Paulo: Anpocs, 1992. In: SCHEEFFER, Fernando. Teoria da escolha racional: a evidenciação do homo economicus? Revista Eletrônica dos Pós-Graduandos em Sociologia Política da UFSC. Florianópolis. v. 10, n. 1, jan./jun., 2013, ISSN 1806-5023, p. 35-36.

CLEAVER, Frances. Institutions, Agency and the Limitations of Participatory Approaches to Development'. In: COOKE, Bill; KOTHARI, Uma. Participation: The New Tyranny? London: Zed Books, 2001.

COULAGENS, Fustel de. A cidade antiga, tradução de Jonas Camargo Leite e Eduardo Fonseca. Rio de Janeiro: Ediouro, 8. ed., s/d., p. 37.

COWDEN, Mhairi. Children`s rights: from philosophy tu public policy. London: Palgrave Macmillan, 2016.

COMMITTEE ON THE RIGHTS OF THE CHILD, 2013, parag. 99, 2013. General Comment $\mathrm{N}^{\mathrm{o}} 14$, The right of the child to have his or her best interests taken as a primary consideration. Disponível em: <http://tbinternet.ohchr.org/_layouts/treatybodyexternal/ Download.aspx? symbolno $=\mathrm{CRC} \% 2 \mathrm{fC} \% 2 \mathrm{fGC} \% 2 \mathrm{f} 14 \& \mathrm{Lang}=\mathrm{em}>$. Acesso em: 22 out 
2017.

CONSTITUTION OF THE REPUBLIC OF SOUTH AFRICA, 1996 - Chapter 2: Bill of Rights. Disponível em: <http://www.gov.za/documents/constituition/chapter-2-billrights\#28> Acesso em: 20 jun. 2017.

COSTA, Tarcísio José Martins. Adoção Transnacional: um estudo sociojurídico comparativo da legislação atual. Belo Horizonte: Del Rey, 1998, p. 185.

CRIN. Myanmar: National laws. Disponível em:< https://www.crin.org/en/ library/publications/myanmar-national-laws> Acesso em: 25 jun. 2017.

Sout Africa: National laws. Disponpivel em: $<$ https://www.crin.org/en/ library/publications/south-africa-national-laws> Acesso em: 25 jun. 2017.

. Costa Rica: national laws. Disponível em:< https://www.crin.org/ en/library/publications/costa-rica-national-laws> Acesso em: 20 jun. de 2017.

. Ireland: National laws. Disponível em: $<$ https://www.crin.org/en/library/ publications/ireland-national-laws $>$ Acesso em: 20 jun. 2017.

. Netherlands: National laws. Disponível em: $<$ https://www.crin.org/en/

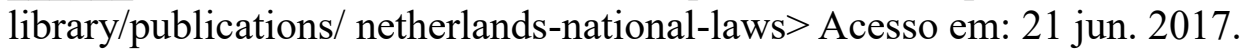

. France: National laws. Disponível em: $<$ https://www.crin.org/en/library/ publications/france-national-laws> Acesso em: 21 jun. 2017.

. Greece: National laws. Disponível em: $<$ https://www.crin.org/en/library/ publications/greece-national-laws $>$ Acesso em: 21 jun. 2017.

. Australia: National laws. Disponível em: $<$ https://www.crin.org/en/library/ publications/australia-national-laws> Acesso em: 21 jun. 2017.

. New Zealand: National laws. Disponível em: $<$ https://www.crin.org/en/library/ publications/new-zealand-national-laws> Acesso em: 21 jun. 2017.

. Pakistan: National laws. Disponível em: < https://www.crin.org/en/library/ publications/pakistan-national-laws> Acesso em: 21 jun. 2017.

Afghanistan: National laws. Disponível em: < https://www.crin.org/en/libary/ publications/ afghanistan-national-laws>. Acesso em: 21 jun. 2017.

CUNHA, Elizabeth. The potential importance of incorporating online dispute resolution into a universal mediation model for international child abduction cases. Connecticut Journal of International Law, Vol. 24:155, 2008-2009.

DE WINTER, Micha. Children as fellow citizens: participation and commitment. Bath: Radcliffe Medical Press Ltd., 1997, p. 4.

DIAS, Maria Berenice. Manual de direito das famílias. 12. ed., rev., atual. e ampl. São 
Paulo: Editora Revista dos Tribunais, 2017, p. 429.

DIDIER JR, Fredie. Os Três Modelos de Direito Processual: Inquisitivo, Dispositivo e Cooperativo. In: Revista de Processo, v. 36, n. 198, p. 213-225, ago. 2011. São Paulo: Revista dos Tribunais. Disponível em: < https://bdjur.stj.jus.br/jspui/bitstream/2011/ 80945/tres_modelos_direito_didier_jr.pdf>. Acesso em: 29 jul. 2017.

. Curso de Direito Processual Civil. Teoria da Prova, Direito Probatório, Ações Probatórias, Decisão Precedente, Coisa Julgada e Antecipação dos Efeitos da Tutela. Vol. 2. 8. ed. rev. atual. Salvador: Juspodivm, 2013, p. 512.

DIREITO, Carlos Alberto Menezes; TRINDADE, Antônio Augusto Cançado; PEREIRA, Antonio Celso Alves (Coord.). Novas perspectivas do Direito Internacion Contemporâneo. Rio de Janeiro: Renovar, 2008.

DITTRICH, Lalisa Froeder. Promoting voluntary agreements in international child abduction disputes: the case of Brazil. International Journal of Law, Policy and the Family. Oxford: Oxford Press University, 2015.

DOLINGER, Jacob. Direito Internacional Privado: A criança no Direito Internacional. Rio de Janeiro: Renovar, 2003.

DOWNS, Anthony. Uma teoria econômica da democracia. São Paulo: EDUSP, 1999.

FEREJOHN, John; PASQUINO, Pasquale. A teoria da escolha racional na ciência política: conceitos de racionalidade em teoria política. Revista Brasileira Ciências Sociais, São Paulo, v. 16, n. 45, fev. 2001, p.7 In: SCHEEFFER, Fernando. Teoria da escolha racional: a evidenciação do homo economicus? Revista Eletrônica dos Pós-Graduandos em Sociologia Política da UFSC. Florianópolis. v. 10, n. 1, jan./jun., 2013, ISSN 1806-5023, p. 34.

FINEMAN, Martha Albertson. WORTHINGTON, Karen. What is Right for Children? The Competing Paradigms of Religion and Human Rights. United Kingdom: Ashgate, 2009.

GAGLIANO, Pablo Stolze; PAMPLONA FILHO, Rodolfo. Novo Curso de Direito Civil, vol. 6: direito de família. 7. Ed. São Paulo: Saraiva, 2017.

GIDDENS, Antony. As consequências da modernidade. São Paulo: Unesp, 1991.

GILISSEN, John. Introdução Histórica ao Direito. 2.ed. Trad. de A. M. Hespanha e L. M. Macaísta Malheiros. Lisboa: Calouste Gulbenkian, 1995.

GREEN, 199. In: HINTON, Rachel. Children`s Participaton and Good Governance: Limitations of the Theoretical Literature. International Journal of Children `s Rights, n. 16, London: Martinus Nijhoff Publishers, 2008, p. 287.

HAFEN, B. Children's liberation and the New Egalitarianism: Some Reservations about Abandoning Youth to their Rights. Bringham Young University Law Review, 1976, p. 605658 . 
HANNUM, Hurst (Editor). Guide to international human rights practice. 2. ed. Philadelphia: University of Pennsylvania Press, 1992.

HAIA, 1996. A Convenção de Haia Concernente à Competência, Lei Aplicável, Reconhecimento, Execução e Cooperação em Matéria de Responsabilidade Parental e Medidas de Proteção da Criança de 1996. Disponível em: <https://assets.hcch.net/ docs/f16ebd3d-f398-4891-bf47-110866e171d4.pdf>. Acesso em: 15 out. 2017.

HART, Jason. Children's Participation and International Development: Attending to the Political. International Journal of Children's Rights, 16, Londres: Martinus Nijhoff Publishers, 2008, p. 407-418.

HART, Roger. Children's Participation: From Tokenism to Citizenship. Itália: Unicef International Child Development Centre, 1992, p. 6.

Children Changing their world: understandind and evaluating children`s participation in development. London: Plan, 2004.

HAGUE. Practical Handbook on the operation of the Hague Convention of 19 October 1996 on Jurisdiction, Applicable Law, Recognition, Enforcement and Co-operation in Respect of Parental Responsibility and Measures for the Protection of Children. Hague: The Hague Conference on Private International Law Permanent Bureau, 2014, p. 105.

HCCH. Hague Convention Child Protection. September 2008 (p. 1). The Hague Convention of 1996 on the International Protection of Children. Disponível em: $<$ https://assets.hcch.net/docs/be4083a2-ed90-4dc2-bb97-13be22e6a5d8.pdf $>$ Acesso em: 27 de dez. 2017.

. Guia de Boas Práticas nos Termos da Convenção da Haia de 25 de outubro de 1980 sobre os aspectos civis de rapto internacional de crianças - Mediação. Publicado pela Conferência da Haia de Direito Internacional Privado, Secretariado Permanente. 2012. Disponível em: <ww.hcch.net/upload/mediation_pt.pdf>. Acesso em: 28 maio 2015.

HEARST, Alice. Children, International human rights, and the politics of belonging. Chapter 17/ In: FINEMAN, Martha Albertson. WORTHINGTON, Karen. What is right for children? The competing paradigms of religion and human rights. United Kingdom: Ashgate, 2009, p. 329.

HINTON, Rachel. Children`s Participaton and Good Governance: Limitations of the Theoretical Literature in. International Journal of Children `s Rights, n. 16. Netherlands: Martinus Nijhoff Publishers, 2008, p. 285-300.

IBDFAM. Reconhecimento de filiação socioafetiva sem necessidade de adoção. Disponível em: $<$ http://www.ibdfam.org.br/noticias/6312/Reconhecimento+de+filia $\%$ C3\%A7\% $\mathrm{C} 3 \% \mathrm{~A} 3 \mathrm{o}+$ socioafetiva + sem + necessidade + de + ado\%C3\%A7\%C3\%A3o.> Acesso em: 27 de dez. 2017.

JAYME, Erik. Le droit international privé du nouveau millénaire: la protection de la personne humaine face à la globalisation. Recueil des Cours. The Hague/Boston/London: Martinus Nijhoff Publishers, 1995. 
. O direito internacional privado no novo milênio: a proteção da pessoa humana em $\overline{\text { face da }}$ globalização. In: ARAUJO, Nadia de; MARQUES, Claudia Lima (Org.). O novo direito internacional: estudos em homenagem a Erik Jayme. Rio de Janeiro: Renovar, 2005. p. 03-20.

KINGDON, John W. Agendas, alternatives, and public policies. New York: Harper Collins, 1984.

KIRBY Perpetua; LANYON, Claire; CRONIN, Kathleen; SINCLAIR, Ruth. Building $a$ Culture of Participation. Involving children and young people in policy, service planning, delivery and evaluation. London: Department for Education and Skills, 2003.

LAFER, Celso. A reconstrução dos direitos humanos. Um diálogo com o pensamento de Hannah Arendt. São Paulo: Companhia das Letras, 1998.

LAGARDE, Paul. Explanatory Report on the 1996 Hague Child Protection Convention. Haia, 1998. Disponível em: <https://www.hcch.net/en/publications-and-studies/details4/ ?pid=2943> . Acesso em: 10 ago. 2017.

LANSDOWN, Gerison. International developments in children`s participation: lesson and challenges. In: TISDALL, E. Kay; M. DAVIS, John; PROUT, Alan; HILL, Malcolm. Children, Young People and Social Inclusion, Participation for What? Bristol: Policy Press, 2006.

LANSDOWN, Gerison. The evolving capacities of the child. Florence: UNICEF/Save the Children: Florence, 2005.

. Promoting children's participation in democratic decision-making. Florence: UNICEF Innocenti Insight, 2001.

LEWANDOWSKI, Enrique Ricardo. Globalização, regionalização e soberania. São Paulo: Juarez de Oliveira, 2004.

LIBERATI, Wilson. Manual da Adoção Internacional. 2. ed. São Paulo: Malheiros, 2009.p. 17-18.

LISBOA. Tratado de Lisboa - Versão Consolidada. Lisboa: Assembleia da República, 2008, p. 18. Disponível em: < https://www.parlamento.pt/europa/Documents/

Tratado_Versao_Consolidada.pdf $>$. Acesso em: 22 abr. 2017.

LLOYD, Demause. The History of Childhood. New York: Psychohistory Press, 1974. Lua Nova, n. 76, 2009.

LOWE, Nigel; MURCH, Mervyn. Translating Principles into Practive. In. DEWAR, John; PARKER, Stephen. (editors) Family Law: processes, practives, pressures. London: Hart Publishing, 2003. p. 17-18.

LOWE, Nigel; HOROSOVA, K. (2007). In DITTRICH, Lalisa Froeder. Promoting Voluntary Agreements in International Child Abduction Disputes: The Case of Brazil. 
International Journal of Law, Policy and the family. Oxford: Oxford Press University, 2015.

MARQUES, Cláudia Lima. A Subsidiariedade da Adoção Internacional: Diálogo entre a Convenção de Haia de 1993, o ECA e o Novo Código Civil Brasileiro. In: LEITE, Eduardo de Oliveira; HIRSCHFELD, Adriana Kruchin. Adoção, Aspectos Jurídicos e Metajurídicos. Rio de Janeiro: Forense, 2005.

MARQUES, Cláudia Lima; ARAUJO, Nadia de. O novo direito internacional: estudos em homenagem a Erik Jayme. Rio de Janeiro: Renovar, 2005.

MARSH, David; STORKER, Gerry. Theory and methods in Political Science. 2. ed. Basingstoke et al.: Palgrave Macmillan, 2002.

MATTHEWS, Huges. Children and Regeneration: Setting an Agenda for Community Participation and Integration. In: Children and Society, v. 17, n. 4, set. 2003, p. 264-276.

MAYO, M. Children's and young people`s participation in development in the south and urban regeneration in the North. In: Progress in Development Studies. v. 1, n. 4, Sep., 2001, p. 279-2003.

MCNEISH, D.; NEWMAN, T. Involving children and young people in decision-making, Buckingham: Open University Press, 2002. In: TISDALL, E. Kay; M. DAVIS, John; PROUT, Alan; HILL, Malcolm. Children, Young People and Social Inclusion, Participation for What? Bristol: Policy Press, 2006, p. 77.

MEDIATION in international parental child abduction. The reunite mediation pilot Scheme. Reunite International Child Abdcution Centre. United Kingdon. 2006. Disponível em: < http://www.reunite.org/edit/files/Library\%20\%20reunite\% $\%$. Acesso em: 10 jun. 2015.

MELUCCI, Alberto. A invenção do presente: movimentos sociais nas sociedades complexas. Petrópolis: Vozes, 2001.

MERTUS, Jennifer. Barriers, Hurdles, and Discrimination: The Current Status of LGBT Intercountry Adoption and Why Changes Must Be Made to Effectuate the Best Interests of the Child. Columbus: Capital University Law Review, 2011, v. 39. Disponível em: <http://bit.ly/Jy5jhv>. Acesso em: 04 jun. 2015.

MILNE, Brian. The History and Theory of Children`s Citizenship in Contemporary Societies. New York: Springer, 2013, p. 60.

MINISTÉRIO DA JUSTIÇA E DOS DIREITOS HUMANOS. Carta Africana dos Direitos e Bem-Estar da Criança. Disponível em: < http://www.achpr.org/pt/instruments/child/>. Acesso em: 22 abr. 2017.

MONACO, Gustavo Ferraz de Campos. A Proteção da Criança no Cenário Internacional. Belo Horizonte: Del Rey, 2005, p. 179. 
2002, p. 32.

Direitos da Criança e Adoção Internacional. São Paulo: Revista dos Tribunais,
2013.
Controle de Constitucionalidade da Lei Estrangeira. São Paulo: Quartier Latin,

MONACO, Gustavo Ferraz de Campos; CAMPOS, Maria Luiza Ferraz de. O direito de audição de crianças e jovens em processo de regulação do exercício do poder familiar. In: Infância e Juventude. Lisboa, n. 1, p. 9-25, 2006.

MORGENTHAU, Hans Joachim. A politica entre as nações: a luta pelo poder e pela paz. Brasília: Ed. UnB, 2003.

MOSSE, D. (2001) People's Knowledge, Participation and Patronage: Operations and Representations in Rural Development. In: COOKE, Bill; KOTHARI, Uma. Participation: The New Tyranny? London: Zed Books, 2001. p. 16-35.

MOURA RAMOS, Rui. Direito Internacional privado e Constituição: introdução a uma análise das suas relações. Coimbra: Coimbra, 1994.

NEWELL, Sallie; GRAHAM, Anne; FITZGERALD, Robyn. Results of an International Survey regarding Children's Participation in Decision-Making Following Parental Separation. Prepared for Childwatch International Research Network's Children \& the Law Thematic Study Group; November 2009. Disponível em: < https://epubs.scu.edu.au/ cgi/viewcontent.cgi?article=1350\&context=educ_pubs $>$ Acesso em: 14 dez. 2017.

NYGH, Peter. The Hague Convention on the protection of the children. Netherlands international law review. The Hague, v. 45, n. 1, 1998, p. 12-13. In: MONACO, Gustavo Ferraz de Campos. Guarda Internacional de Crianças. São Paulo: Quartier Latin, 2012, p. 139.

OLSON, Mancur. A lógica da ação coletiva: os benefícios públicos e uma teoria dos grupos sociais. São Paulo: EDUSP, 1999.

PAES, Marta Santos. A Convenção dos Direitos da Criança (quadro inspirador de uma política global para a infância). Documentação e Direito Comparado, Lisboa, n. 55-56, 1993, p. 212.

PAGANINI, Juliana. A Democracia Participativa e o princípio da Participação popular como mecanismos de proteção dos direitos fundamentais da criança e do adolescente. Trabalhado apresentado na VII Mostra de Trabalhos Jurídicos Científicos do XI Seminário Internacional de Demandas Sociais e Políticas Públicas na Sociedade Contemporânea. Santa Cruz do Sul: UNISC, 2014. Disponível em < http://online.unisc.br/acadnet/anais/ index.php/sidspp/article/view/11715/1625>. Acesso em 10 de fev. de 2016. p. 94.

Child Participation. Documentação e Direito Comparado, Lisboa, n. 81-82, 2000,

PARRA-ARANGUREN, Gonzalo. Explanatory report on the convention on protection of children and co-operation in respect of intercountry adoption. Disponível em: <www.hcch. 
net/upload/expl33e.pd>. Acesso em: 18 jul. 2017, p. 20-21.

PARKES, Aisling. Children and international human rights law: the right of the child to be heard. New York: Routledge, 2015, p. 8.

PERES LUÑO, Antônio. Derechos humanos, estado de derecho y constitucion. 5. ed. Madrid: Tecnos, 1995. In: CARVALHO RAMOS, André de. Teoria geral dos direitos humanos na ordem internacional. 2. ed. São Paulo: Saraiva, 2012.

PEREZ-VERA, Elisa. Explanatory Report on the 1980 Hague Child Abduction. Offprint from the Acts and Documents of the Fourteenth Session (1980), tome III, Child abduction, 1982. Disponível em: < https://www.hcch.net/pt/publications-and-studies/details4/?pid= 2779> Acesso em: 4 de nov. de 2017.

PETERS, Jean Koh. How Children are heard in child protective proceeding, in the United States and around the world in 2005: Survey Findings, Initial Observations, and areas for further study. In: Nevada Law Journal, Spring, 2006, vol. 6:966, p. 969.

PIOVESAN, Flávia. Temas de Direitos Humanos. 6. ed. São Paulo: Saraiva, 2013, p. 410.

. Tratados Internacionais de proteção dos direitos humanos: jurisprudência do STF. In: Revista Internacional Direito e Cidadania. $\mathrm{n}^{\mathrm{o}}$ 1, 2008. Disponível em: $<\mathrm{http}: / / \mathrm{www}$. reid.org.br/arquivos/00000034-001_FlaviaPiovesan.pdf >. Acesso em: 04 abr. 2016.

. Direitos Humanos e o Direito Constitucional Internacional. 14. ed. São Paulo: Saraiva, 2013.

POLLOCK, Linda. Forgotten Children. Parent-child relations from 1500 to 1900. Cambridge: Cambridge University Press, 1983.

PROUT, Alan; JAMES, Allison. A new paradigm for the sociology of childhood Provenance, promises and problems. In: Constructing and Reconstructing childhood, London: Falmer, 1990.

PROUT, Alan; SIMMONS, Richard; BIRCHALL, Johnston. Reconnecting and extending the research agenda on children's participation: mutual incentives and the participation chain. In: TISDALL, E. Kay; M. DAVIS, John; PROUT, Alan; HILL, Malcolm. Children, Young People and Social Inclusion, Participation for What? Bristol: Policy Press, 2006.

RAMOS, Patrícia Pimentel de Oliveira Chambers. Poder Familiar e a guarda Compartilhada: novos paradigmas do direito de família. 2. ed. São Paulo: Saraiva, 2016. p. $42-45$.

RIBEIRO, Geraldo Rocha. Rapto Internacional: o problema internacional e instrumentos de resolução. In. O Direito Internacional da Família Tomo I. Lisboa: Centro de Estudos Judiciários, junho de 2014. p. 137-159.

ROCHE, Jeremy. The Children Act 1989 and children`s rights: a critical reassesment. In: FRANKLIN, Bob. (Ed.) The New Handbook of Children's Rights Comparative Policy and Practice. London: Routledge, 2002. 
RODAS, João Grandino. Direito Internacional privado brasileiro. São Paulo: RT, 1993.

SECRETARIADO NACIONAL DO APOSTOLADO DA ORAÇÃO. Código de Direito Canônico. Disponível em: < http://www.vatican.va/archive/cod-iuris-canonici/cic_index 1t.html>. Acesso em: 30 abr. 2016.

OTTOMAYOR, Maria Clara Pereira de Sousa. Regulação do exercício do poder paternal nos casos de divórcio. 4. ed. rev. aum. e actual. Coimbra: Livraria Almedina, 2002. p. 16.

Quem são os verdadeiros pais? Adopção plena de menor e oposição dos pais biológicos. In: Direito e Justiça. Faculdade de Direito da Universidade Católica Portuguesa, v. XVI, 2002, p. 191-214.

. Divórcio, poder parental e realidade social: algumas questões. In: Direito e Justiça. Revista da Faculdade de Direito da Universidade Católica Portuguesa, Lisboa, v. 11, n. 2, pp. 161-172, 1997. apud. MONACO, 2012, op. cit., p. 89.

SOUZA, Gustavo Henrique Campos. A Adoção Internacional no direito comunitário europeu: uma análise crítica do caso Romênia. In: MOURA RAMOS, Rui Manuel; MONACO, Gustavo Ferraz de Campos de (Org.) Aspectos da unificação europeia do direito internacional privado. São Paulo: Intelecto Editora, 2016, p. 351.

STALFORD, H. Children and the European Union: Rights, welfare and Accountability. Oxford: Hart Publishing, 2012, p. 222.

STHOEGER, Eran. Internacional Child Abduction and Children`s Rights: two means to the same end. In: Michican Journal of International Law. v. 32, issue 3, 2011. p. 525.

TEPEDINO, Gustavo. A disciplina jurídica da filiação na perspectiva constitucional. Temas de Direito civil. Rio de Janeiro: Renovar, 1999. p. 392.

THE CONSTITUTION OF THE REPUBLIC OF POLAND, 1997. The Constitution shall be the supreme law of the Republic of Poland. The provisions of the Constitution shall apply directly, unless the Constitution provides otherwise. Disponível em: $<\mathrm{http}: / \mathrm{www}$. senat.gov.pl/en/about-the-senate/konstytucja/> Acesso em: 25 jun. 2017.

THOMAS, Nigel. Towards a Theory of Children`s Participation. In: International Journal of Children `s Rights, n. 15. Londres: Martinus Nijhoff Publishers, 2007, p. 199-218.

Children. Family and the State: decision-making and child participation, Bristol:

The Policy Press, 2002.

TIBURCIO, Carmen, CALMON, Guilherme. Sequestro internacional de crianças: comentários à Convenção de Haia de 1980. São Paulo: Atlas, 2014.

TISDALL, E. Kay; M. DAVIS, John; PROUT, Alan; HILL, Malcolm. Children, Young People and Social Inclusion, Participation for What? Bristol: Policy Press, 2006.

TRESEDER, Phil. Empowering children and young people training manual: promoting involvement in decision-making. London: Save the Children, 1997. 
UNICEF. Summary Report of the Study on the impact of the implementation of the Convention on the Rights of the Child. Florence, Italy: UNICEF, 2004. Disponivel em: < https://www.unicef-irc.org/publications/pdf/CRC_Impact_summaryreport.pdf $>$. Acesso em 1 jul. 2017.

. Myanmar - Child protection. Strengtheing Legislationa. Disponível em:

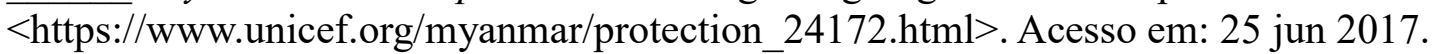

UNITED NATIONS. Resolution Adopted by the General Assembly. 1386 (XIV).

Declaration of the Rights of the Child. Disponivel em: $<$ http://www.undocuments.net/ a14r1386.htm>. Acesso em: 2 nov. 2017.

. Treaty Collection. 11. Convention on the Rights of the Child. Disponível em:

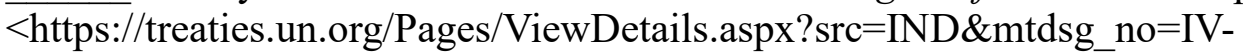
$11 \&$ chapter=4\&lang=en. $>$ Acesso em: 12 jun. 2016.

. Committee on the rights of the child. Fifty-first session. General Comment $\mathrm{N}^{\mathrm{o}} 12$. The right of the Child to be Heard. Geneva: 2009.

General Comment No. 5 - General measures of implementation of the Convention of the Rights of the Child (arts. 4, 42 and 44, para.6), 2003. Disponível em: $<$ http://repository.un.org/handle/11176/247127>. Acesso em: 18 jun. 2017.

VILLÁN DURÁN, Carlos. Curso de derecho internacional de los derechos humanos. Madrid: Trotta, 2002, p. 85.

YALE LAW SCHOOL. Representing Children Worldwide How Children's voices are heard in child protective proceedings, 2005. Disponível em: <http://rcww.law.yale.edu/ index.htm>. Acesso em 15 out 2016. In. PETERS, Jean Koh. How children are heard in child protective proceedings, in the United States and aorund the world in 2005: survey findings, initial observations and areas for further study. Nevada Law Journal, Vol. 6, Spring 2006.

WARD, Hugh. Rational choice. London, New York: Palgrave Mcmillan, 2002. In: MARSH, David; STORKER, Gerry. Theory and methods in Political Science. 2. ed. Basingstoke et al.: Palgrave Macmillan, 2002. p. 65-89. 